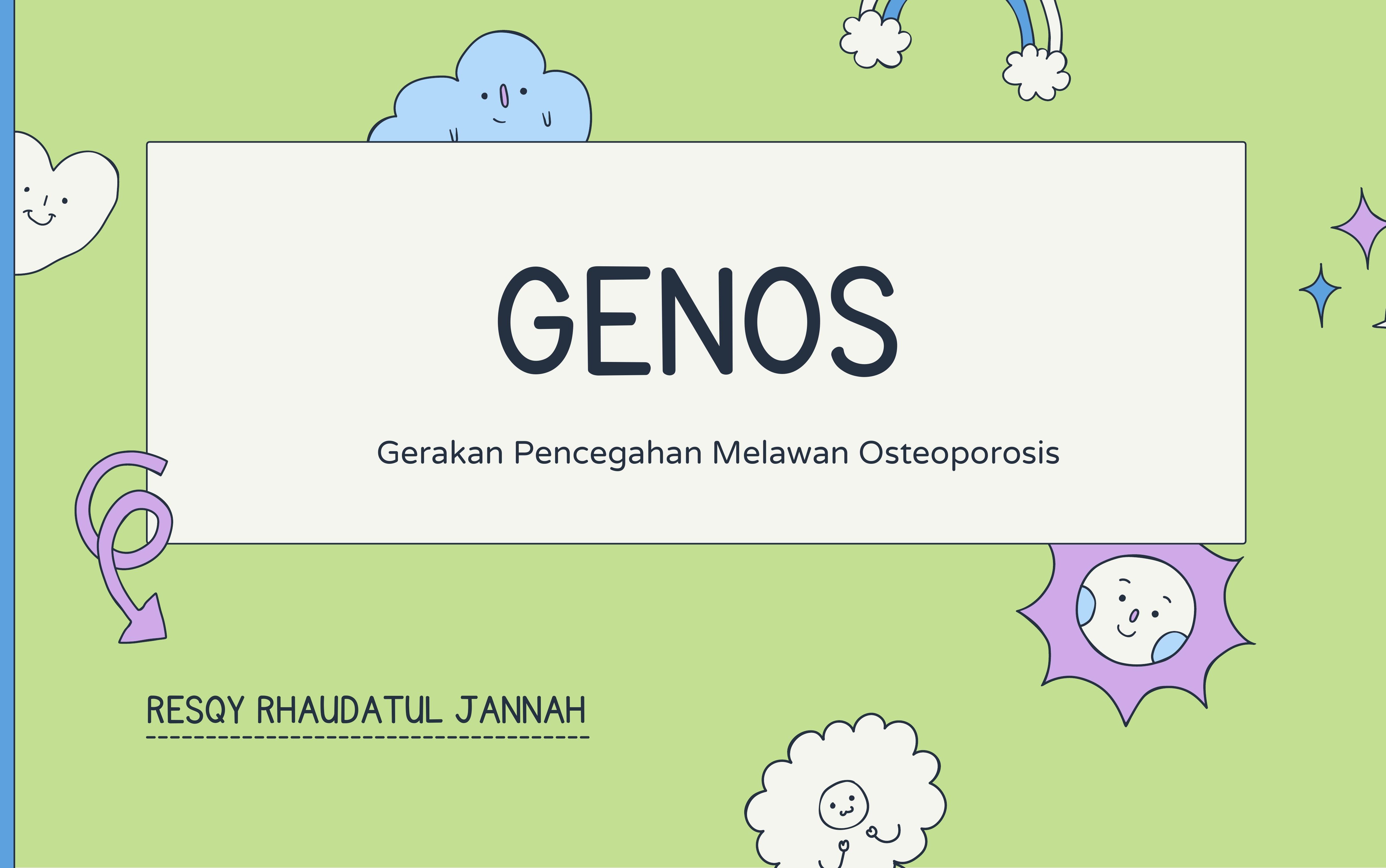


Osteoporosis adalah penyakit ketike
tulang secara perlahan kehilangan kepadatannya, sehingga menjadi lemah dan rentan akan fraktur (patah tulang). Osteoporosis paling sering menyebabkan fraktur di panggul, tulang belakang, dan pergelangan tangan.
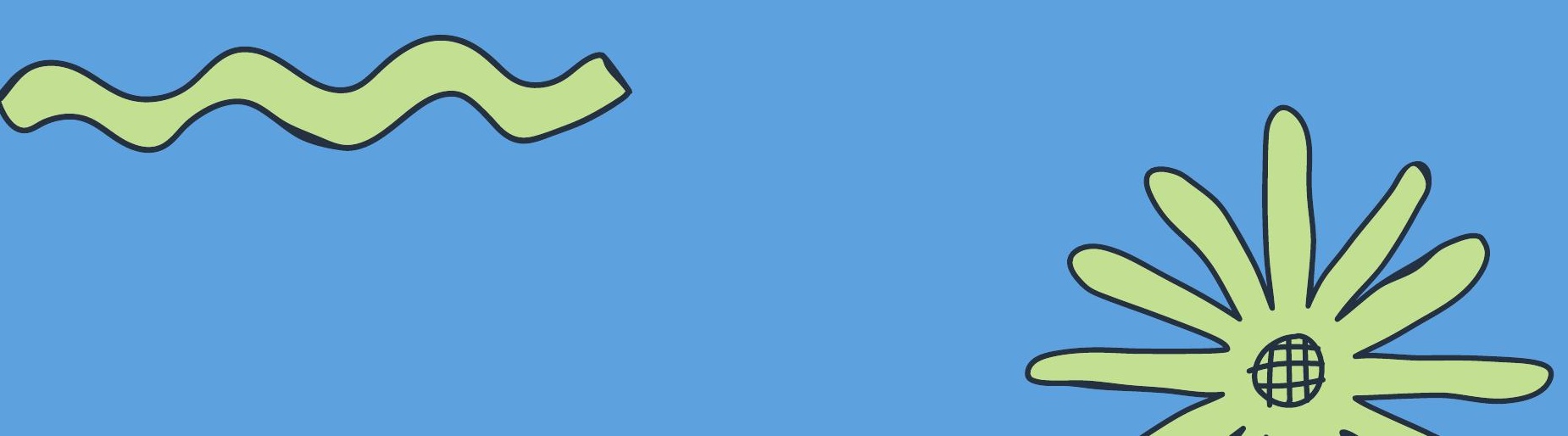


\section{Dasar Masalah}

Berdasarkan data the World Health Organization (WHO) dan International Osteoporosis Federation (IOF), penderita Osteoporosis di dunia lebih dari 200 juta orang, dan 50 persen kejadian patah tulang disebabkan oleh Osteoporosis yang dapat memicu terjadinya kecacatan seumur hidup hingga kematian.

Saat ini Osteoporosis (penyakit tulang keropos) masih menjadi masalah kesehatan masyarakat di dunia terutama di negara berkembang. Untuk itu, Gerakan Pencegahan Melawan Oteoporosis harus mendapat dukungan dari seluruh lapisan masyarakat di tanah air 


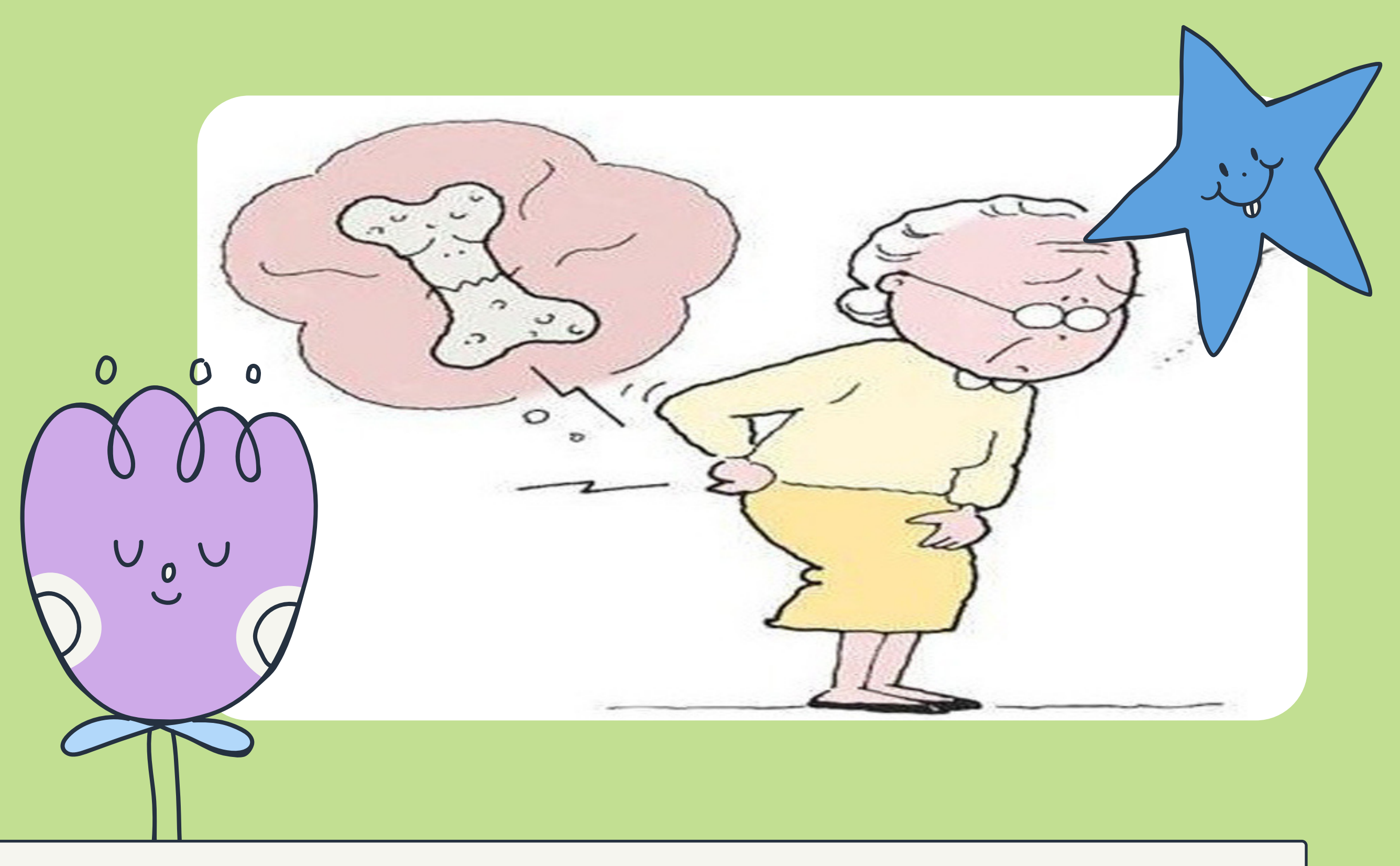

GERAKAN PENCEGAHAN MELAWAN OSTEOPOROSIS

tidak hanya bertujuan mengobati tetapi yang lebih penting melakukan pencegahan baik dengan aktivitas olahraga maupun asupan nutrisi yang baik setiap hari 


\section{SASARAN}

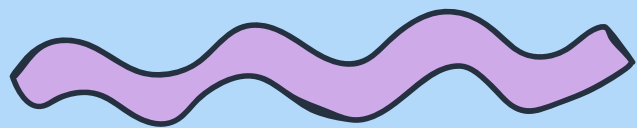

SELURUH MASYARAKAT TERUTAMA PADA USIA >20 TAHUN
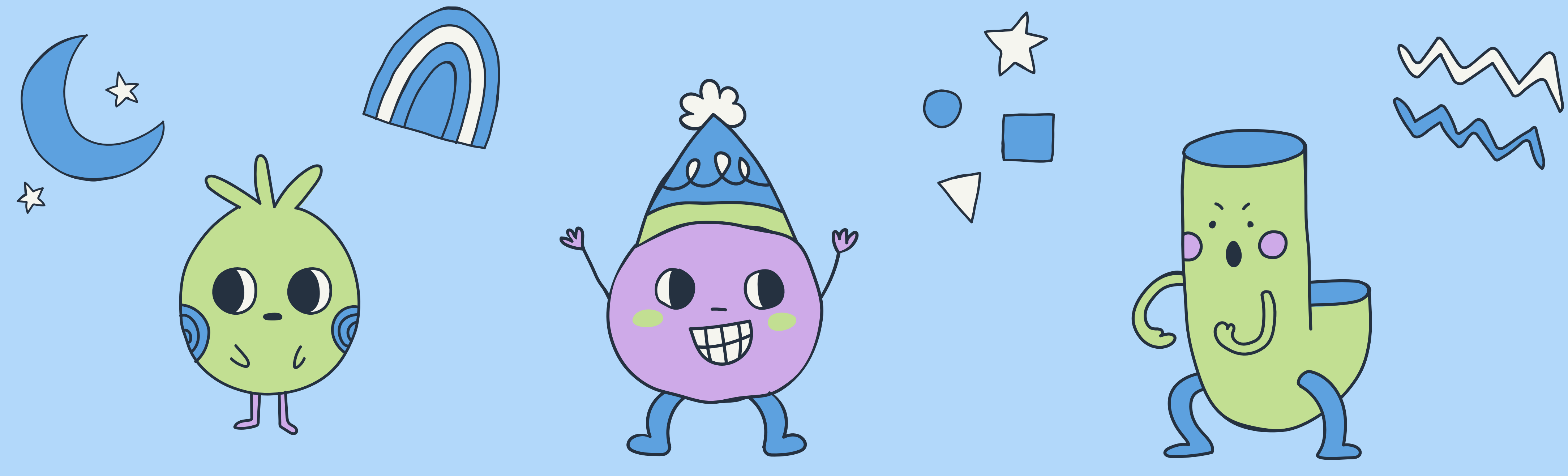

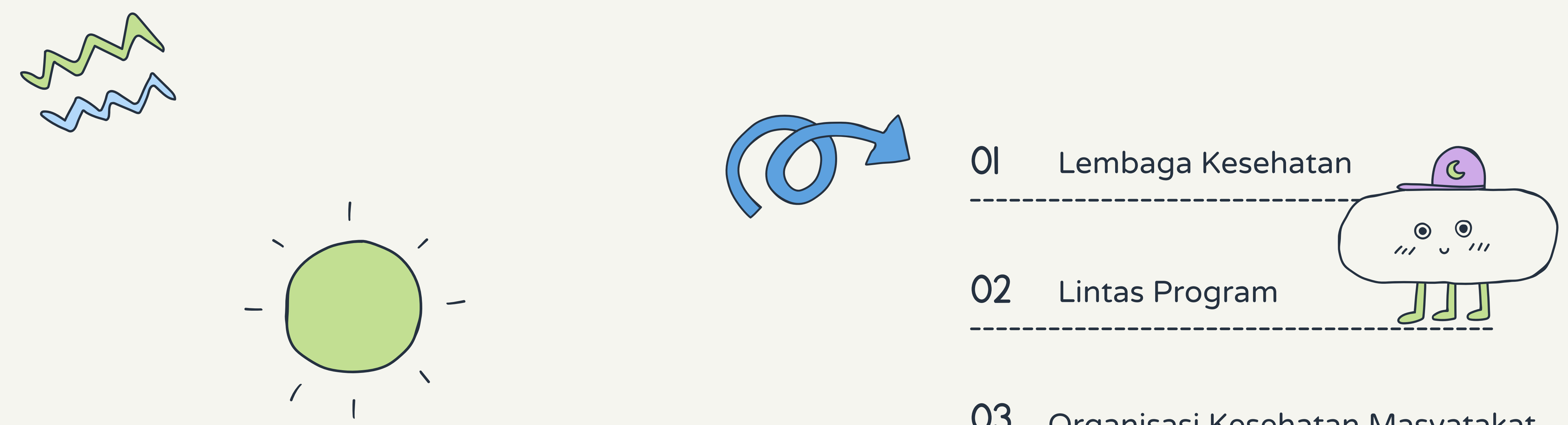

\section{Kemitraan}

03 Organisasi Kesehatan Masyatakat

04 Lembaga Swadaya Masyarakat

05 Pihak Swasta/Negeri

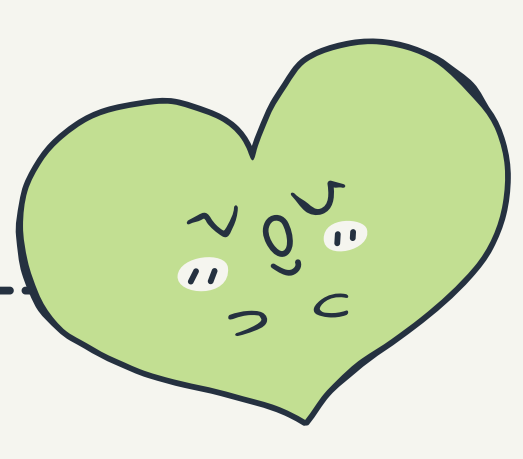




\section{Kegiatan}
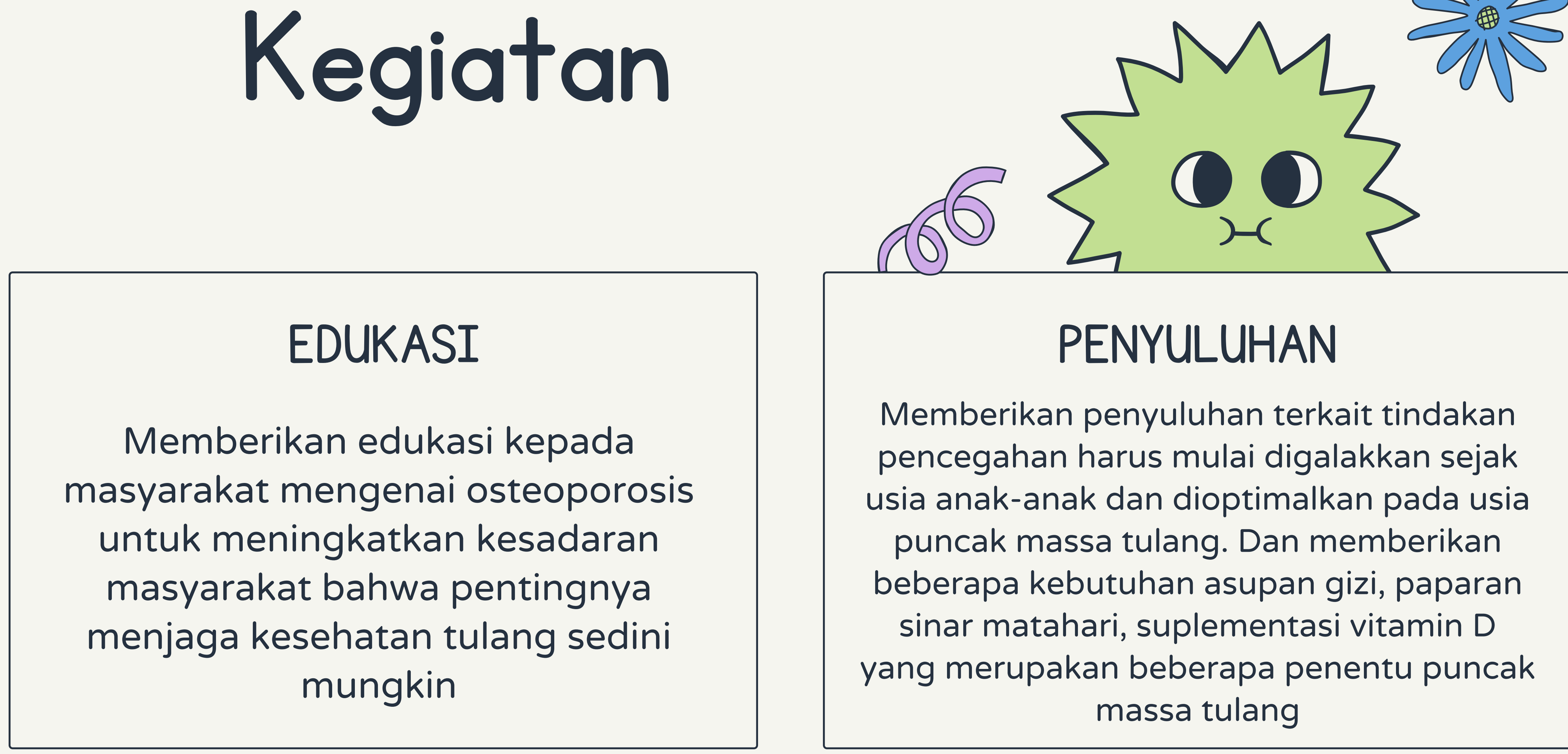

Memberikan penyuluhan terkait tindakan pencegahan harus mulai digalakkan sejak usia anak-anak dan dioptimalkan pada usia puncak massa tulang. Dan memberikan beberapa kebutuhan asupan gizi, paparan sinar matahari, suplementasi vitamin D yang merupakan beberapa penentu puncak massa tulang 


\section{Potensi Masyarakat@}

Masyarakat perlu menyikapi dan mendapat perhatian secara serius, mengingat Osteoporosis merupakan penyakit yang tidak hanya diderita oleh sebagian besar wanita yang telah menopause, namun juga dapat menyerang siapapun, tidak hanya lansia namun juga kelompok usia muda 


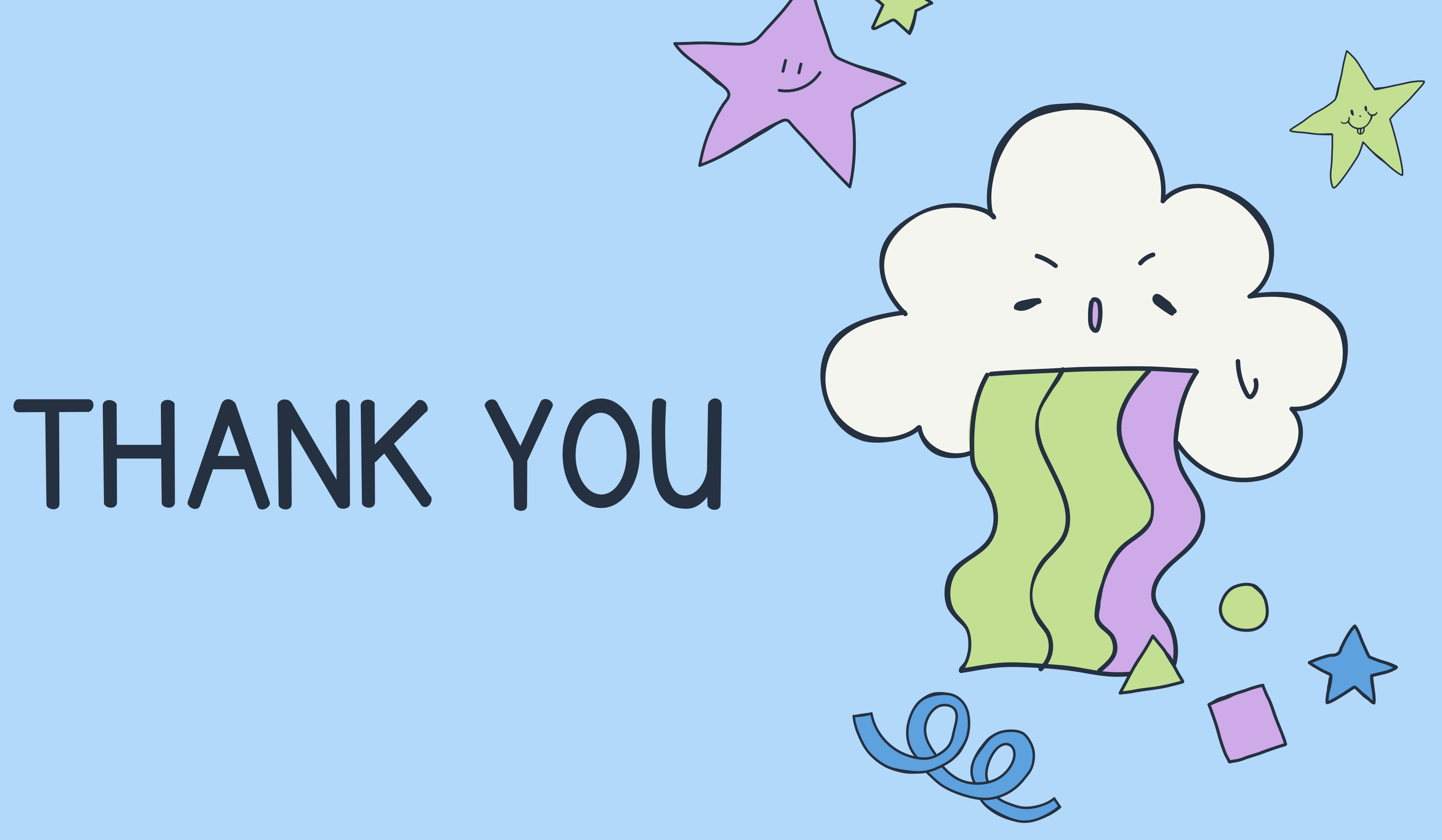

